\title{
The Real Exchange Rate and Growth Revisited: The Washington Consensus Strikes Back?
}

Andrew Berg and Yanliang Miao 


\title{
IMF Working Paper
}

Research Department and African Department

\section{The Real Exchange Rate and Growth Revisited: The Washington Consensus Strikes Back?}

\author{
Prepared by Andrew Berg and Yanliang Miao ${ }^{1}$
}

March 2010

\begin{abstract}
This Working Paper should not be reported as representing the views of the IMF. The views expressed in this Working Paper are those of the author(s) and do not necessarily represent those of the IMF or IMF policy. Working Papers describe research in progress by the author(s) and are published to elicit comments and to further debate.
\end{abstract}

There is good reason and much evidence to suggest that the real exchange rate matters for economic growth, but why? The "Washington Consensus" (WC) view holds that real exchange rate misalignment implies macroeconomic imbalances that are themselves bad for growth. In contrast, Rodrik (2008) argues that undervaluation relative to purchasing power parity is good for growth because it promotes the otherwise inefficiently small tradable sector. Our main result is that WC and the Rodrik views of the role of misalignment in growth are observationally equivalent for the main growth regressions he reports. There is an identification problem: Determinants of misalignment are also likely to be independent drivers of growth, and these types of growth regressions are hard-pressed to disentangle the different channels. However, we confirm that not only are overvaluations bad but undervaluations are also good for growth, a result squarely consistent with the Rodrik story but one that requires some gymnastics from the $\mathrm{WC}$ viewpoint.

JEL Classification Numbers: D90; F31;

Keywords: Real Exchange Rate; Growth; Washington Consensus Author's E-Mail Address: aberg@imf.org; ymiao@,imf.org

\footnotetext{
${ }^{1}$ The authors are grateful for useful comments from and discussions with Stan Fischer, Gian-Maria Milesi-Ferretti, Jonathan Ostry, Chris Papageorgiou, Luca Ricci, Dani Rodrik, and Abe Selassie. Any remaining errors or omissions are our own.
} 
I. Introduction-A Horse Race ..................................................................................

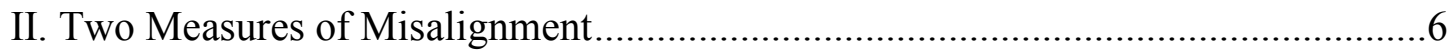

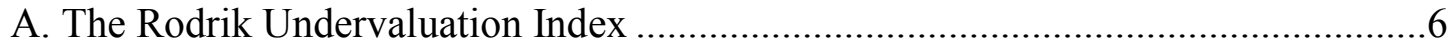

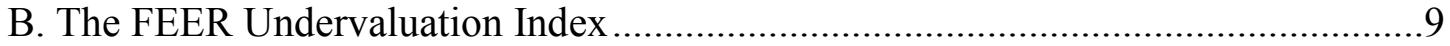

III. Which Misalignment Definition Matters for Growth? .......................................11

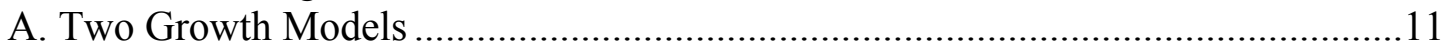

B. A Horse Race Between PPP- and FEER-Based Concepts of Misalignment?.........13

IV. Undervaluation vs Overvaluation ........................................................... 16

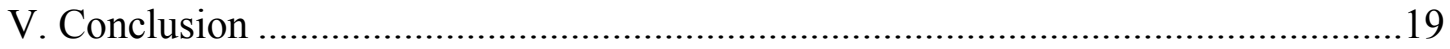

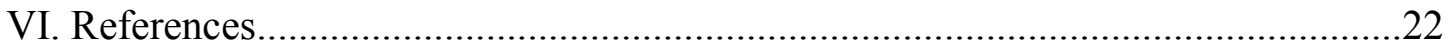

Tables



Table 2. Growth and Undervaluations - A Horse Race...................................................... 12

Table 3. Undervaluation vs Overvaluation ..................................................................... 18

Table 4. Linearity and Symmetry Hypothesis Test ......................................................19

\section{Figures}

Figure 1a. Distribution of PPP-Based Misalignment.................................................... 9

Figure 1b. Distribution of FEER-Based Misalignment ................................................... 10

Figure 2. Plots of the Two Undervaluation Indices .......................................................... 11 


\section{INTRODUCTION-A HORSE RACE}

There is good reason and much evidence to suggest that the real exchange rate matters for economic growth. However, the nature of this relationship and the policy implications are far from settled.

One position - call it the "Washington Consensus" (WC) view-holds that real exchange rate misalignment implies some sort of macroeconomic disequilibrium that is itself bad for growth. For example, fixed exchange rates in the presence of loose monetary policy may cause an appreciating real exchange rate and an unsustainable current account deficit, eventually requiring a domestic contraction or import controls when foreign financing disappears. Krueger (1983) emphasized that such misalignments would reduce the openness of the country to trade and thus growth.

In this view, overvaluation is the main danger, but undervaluation does not help. Rather, undervaluation also represents a harmful misalignment that will need to be corrected, and this correction may also be bad for growth.

This view is summarized in the original WC manifesto (Williamson 1990):

The test of whether an exchange rate is appropriate is whether it is consistent in the medium run with macroeconomic objectives. . . . In the case of a developing country, the real exchange rate needs to be sufficiently competitive to promote a rate of export growth that will allow the economy to grow at the maximum rate permitted by its supply-side potential, while keeping the current account deficit to a size that can be financed on a sustainable basis. The exchange rate should not be more competitive than that, because that would produce unnecessary inflationary pressures and also limit the resources available for domestic investment, and hence curb the growth of supply-side potential. ${ }^{2}$

According to the WC view, real exchange rate misalignment might be measured by comparing the actual real exchange rate to that exchange rate that would be consistent with the mediumterm fundamentals driving the equilibrium exchange rate, such as fiscal policy and the terms of trade. The IMF's “Consultative Group on Exchange Rates” (CGER) approach involves estimating exchange rate misalignment as a deviation from medium-term fundamentals, along the lines of the Williamson (1985) notion of the "fundamental equilibrium exchange rate" or

\footnotetext{
${ }^{2}$ Williamson (1990), "What Washington Means by Policy Reform,” in "Latin American Adjustment: How Much Has Happened?” John Williamson, ed. Washington, Institute for International Economics.
} 
FEER (see IMF2006 and 2008, and, for an extension to low-income countries, Christiansen, and others, 2009). ${ }^{3}$

Much of the broad empirical evidence about exchange rates and growth can be interpreted in terms of the WC view. For example, Sachs and Warner (1995) find "openness" to be a key variable driving growth; this variable in turn depends critically on the black market premium, which is presumably correlated with (official) exchange overvaluation relative to a set of medium-term fundamentals. ${ }^{4}$ Easterly (2005) finds that the black market premium-interpreted as a measure of exchange rate overvaluation - is one of the few reasonably robust policy determinants of growth in a panel regression. Johnson, Ostry, and Subramanian (2007) find evidence that avoidance of exchange rate overvaluations is associated with long growth booms, while undervaluations do not matter. In a more direct test, Aguirre and Calderon (2005) find that exchange rate misalignment — measured as residuals from a FEER regression — helps predict growth in a sample of developed and emerging countries. ${ }^{5}$

Rodrik (2008) makes a dramatically different argument about the reason exchange rate misalignment matters for growth and also about the empirical relationship. His two main empirical findings are both in sharp contrast to the WC view:

A. Growth over the medium term is much higher in countries with more undervalued exchange rates, in a large sample of developing countries over 1950-2004. Undervaluation is defined as any deviation of the real exchange rate from purchasing power parity, after taking into account the fact that poor countries tend to have more devalued exchange rates along the lines of the Balassa-Samuelson effect.

B. The effect is linear and similar for both under- and overvaluation. That is, overvaluation hurts growth, but undervaluation also helps.

He explains these results with models in which an equilibrium appreciation in the FEER sensein particular driven by a higher (permanent) inward transfer - can reduce growth. He articulates two stories, each of which has the feature that externalities make the traded goods sector too

\footnotetext{
${ }^{3}$ The CGER methodology involves three approaches to assessing the equilibrium exchange rate. We focus here on the reduced form equilibrium real exchange rate approach (ERER) method, as described in IMF (2008). This involves single-equation estimation of the level of the real exchange rate that is consistent with a set of fundamentals over the medium term. In the CGER, the real effective exchange rate is typically CPI-based. Here we follow Rodrik in looking at PPP-based measures, but the approach to assessing equilibrium, and hence deviations from equilibrium, is very similar, as is the list of fundamentals. For the latter, we draw in particular on Christiansen et al. (2009).

${ }^{4}$ Rodriguez and Rodrik (1999) emphasize the dependence of the "openness" variable on the black market premium and that this may be related to many aspects of macroeconomic disarray, not just closure to trade. See also Wacziarg and Welch (2003).

${ }^{5}$ Other cross-country studies that draw a link between overvaluation and low growth include Fischer 1993; Razin and Collins 1997; Rajan and Subramanian 2007, and Dollar and Kraay (2003).
} 
small. In one, learning by doing — with benefits extending beyond the firm — is more important in the export sector, such that the equilibrium exchange rate results in lower growth than would a more depreciated exchange rate. In the second, developing countries have poor institutions for contract-intensive activities, and such activities are concentrated in the traded goods sector.

This set of arguments and evidence evokes and is supported by a broad literature derived from some interpretations of the East Asian growth experience (e.g. Dollar 1992). Many have argued, for example, that China's spectacular growth performance in recent decades is in part related to a deliberate policy of keeping the real exchange rate "undervalued." More generally, it is sometimes argued that developing countries need more policy space, in particular to pursue unorthodox strategies such as deliberate undervaluation of the exchange rate.

If Rodrik (2008) is right about the relationship between undervaluation and growth, a number of difficult policy issues arise. For example, the real exchange rate is not in itself a policy instrument, and it is not clear how or at what costs countries might actively pursue such a strategy. Moreover, even if undervaluation benefits one country, there are potential "beggar thy neighbor" implications. ${ }^{6}$ These questions are not the focus of this paper. Rather, we examine a prior question, which is whether the evidence in fact supports the Rodrik or the WC view.

The horizon of analysis is the medium term. In the long run, real exchange rate deviationsespecially relative to fundamental determinants - are not likely to be sustainable essentially by definition. But the notion here is that over five-year periods these deviations can be significant and can matter for growth.

Our approach is to test directly the two competing theories of misalignment and growth, in common empirical framework. First, we create two alternative estimates of exchange rate undervaluation. $\varepsilon_{i t}^{P P P}$ follows exactly Rodrik (2008) and measures the deviation of the real exchange rate from PPP, adjusted for per capita income. $\varepsilon_{i t}^{F E E R}$ controls for additional fundamental determinants of the equilibrium exchange rate beyond income per capita, so it measures deviation of the real exchange rate from a full set of equilibrium determinants - per capita income but also the terms of trade, openness, investment, and government consumption.

It is important to underscore that these are not alternative theories of the behavior of the actual or equilibrium exchange rate. The logic and analysis in Rodrik (2008) is consistent with a FEER model broadly along the lines of that used here, in that the misalignment in his models is an equilibrium outcome of a fundamental determinant (transfers).

Rather, the difference we are attempting to test revolves around the question of which misalignment definition belongs in the growth regression. Thus, we compare the results of using $\varepsilon_{i t}^{P P P}$ and $\varepsilon_{i t}^{F E E R}$ in a standard growth regression.

\footnotetext{
${ }^{6}$ These and other objections are explored in the comments by Henry (2008) and Woodford (2008).
} 
Our main result is that $\mathrm{WC}$ and the Rodrik views of the role of misalignment in growth are observationally equivalent for the main growth regressions. This is not because of data problems or lack of statistical power. Rather, there is an identification problem: It turns the two theories imply very similar regressions, and examination of the significance or size of the coefficients does not tell us which theory is correct. Determinants of misalignment are likely to also be independent drivers of growth, and these types of growth regressions are hard-pressed to disentangle whether it is the misalignment or the direct effect that matters. We attempt to pull more information out of the data through some fairly strong identifying assumptions. Some of this regression evidence suggests that deviations from fundamentals are more important than deviations from PPP.

Looking beyond our horse-race, we confirm that not only are overvaluations bad but undervaluations are also good for growth, a result squarely consistent with the Rodrik story but one that requires some gymnastics from the $\mathrm{WC}$ viewpoint.

The next section describes the two misalignment measures; Section 3 runs the "horserace" between the two different conceptions of misalignment. Section 4 examines the importance of overvaluation vs undervaluation. Section 5 concludes.

\section{TWO MEASURES OF MISALIGNMENT}

\section{A. The Rodrik Undervaluation Index}

Rodrik defines a measure of undervaluation as a deviation of the actual real exchange rate from its purchasing-power-party (PPP) value, adjusted for the effects of per capita income on the real exchange rate. ${ }^{7}$ The real exchange rate is defined as the ratio of the market exchange rate to the PPP conversion factor. An RER of 1 means that the market exchange rate produces the same price levels as in the US (the reference country). "Undervaluation" is then the residual in a regression of the real exchange rate on per capita income, in order to control for the BalassaSamuelson effect. The index format has the advantage that it is comparable across countries as well as over time.

\footnotetext{
${ }^{7}$ The PPP value of the exchange rate is that value that would yield the same price level as in the reference country (the United States) when expressed in a common currency.
} 
Following Rodrik, we define $\varepsilon_{i t}^{P P P}$ as the residual from the following regression:

$$
e_{i t}=\alpha_{0}+\alpha_{1} y_{i t}+\alpha_{t}+\varepsilon_{i t}^{P P P}
$$

where $e_{\mathrm{it}}$ is the $\log$ of the real exchange for country $i$ at time $t, y_{i t}$ is the log of real GDP per capital, and $\alpha_{t}$ is a full set of time dummies.

Our data come from Penn World Tables 6.2 (Heston, Summers, and Atina 2006). We follow Rodrik in excluding several outliers Iraq, Laos, and the People's Republic of Korea and in later dividing the sample into two subsamples: developing countries and developed ones with a real per capita GDP cut-off line of USD 6000. Because the real exchange rate may deviate from fundamental values in the short run, we take five-year average for each data series, yielding a dataset consisting of observations on 181 countries over eleven 5-year time periods from 195054 through 2000-04.

Table 1 shows the results of this regression, both for the larger sample that matches Rodrik (2008)'s regression (the "full sample"), and the smaller sample for which we also have ToT data (the "restricted sample"). The Table also reproduces Rodrik's published results. The undervaluation index $\varepsilon_{i t}^{P P P}$ is centered at 0 , by construction, with a standard deviation of 0.48 (see Figure 1a). ${ }^{8}$

\footnotetext{
${ }^{8}$ Reproducing the Rodrik undervaluation index in our 160 countries sample yields the same standard deviation of 0.48 .
} 
Table 1. The Exchange Rate Regression

Dependent Variable: Real Exchange Rate

(1)

Full Sample
(2)

Restricted Sample
(3)

(4)

FEER

\begin{tabular}{|c|c|c|c|c|}
\hline Real GDP per capita & $\begin{array}{c}-0.23 * * * \\
(-21.72)\end{array}$ & $\begin{array}{c}-0.24 * * * \\
(-20.80)\end{array}$ & $\begin{array}{c}-0.24 * * * \\
\text { "around } 20 \text { " }\end{array}$ & $\begin{array}{c}-0.20^{* * *} \\
(-13.14)\end{array}$ \\
\hline Terms of Trade & & & & $\begin{array}{c}-0.28 * * * \\
(-3.34)\end{array}$ \\
\hline Openness & & & & $\begin{array}{c}0.055^{* *} \\
(2.21)\end{array}$ \\
\hline Government Consumption & & & & $\begin{array}{c}0.40 * * * \\
(2.72)\end{array}$ \\
\hline Investment & & & & $\begin{array}{c}-1.30 * * * \\
(-6.28)\end{array}$ \\
\hline Time Dummies & Yes & Yes & Yes & Yes \\
\hline R-squared & 0.19 & 0.22 & N.A. & 0.31 \\
\hline Observations & 1488 & 1183 & N.A. & 1086 \\
\hline
\end{tabular}

Notes: The real exchange rate, real GDP per capita, and terms of trade are expressed in logarithm terms. For regressors variables in logarithm terms, a coefficient of positive 1 implies that an increase in the variable of one percentage point depreciates the exchange rate by one percentage point. For variables expressed as a share of GDP (openness, government consumption, and investment), a coefficient of positive 1 implies that an increase of the variable from 0 to 1 percent of GDP depreciates the exchange rate by 1 percentage point.

Full sample: the same sample as Rodrik (2008), i.e., countries with all available data in PWT 6.2, excluding outliers Iraq, Laos, and North Korea. Restricted sample: a subset of full sample for which terms of trade data are available (see Christiansen et al. (2009)). Robust t-statistics in parentheses.

$* * *$ significant at $1 \%$ level; ** significant at $5 \%$ level; * significant at $10 \%$ level 
Figure 1a. Distribution of PPP-Based Misalignment

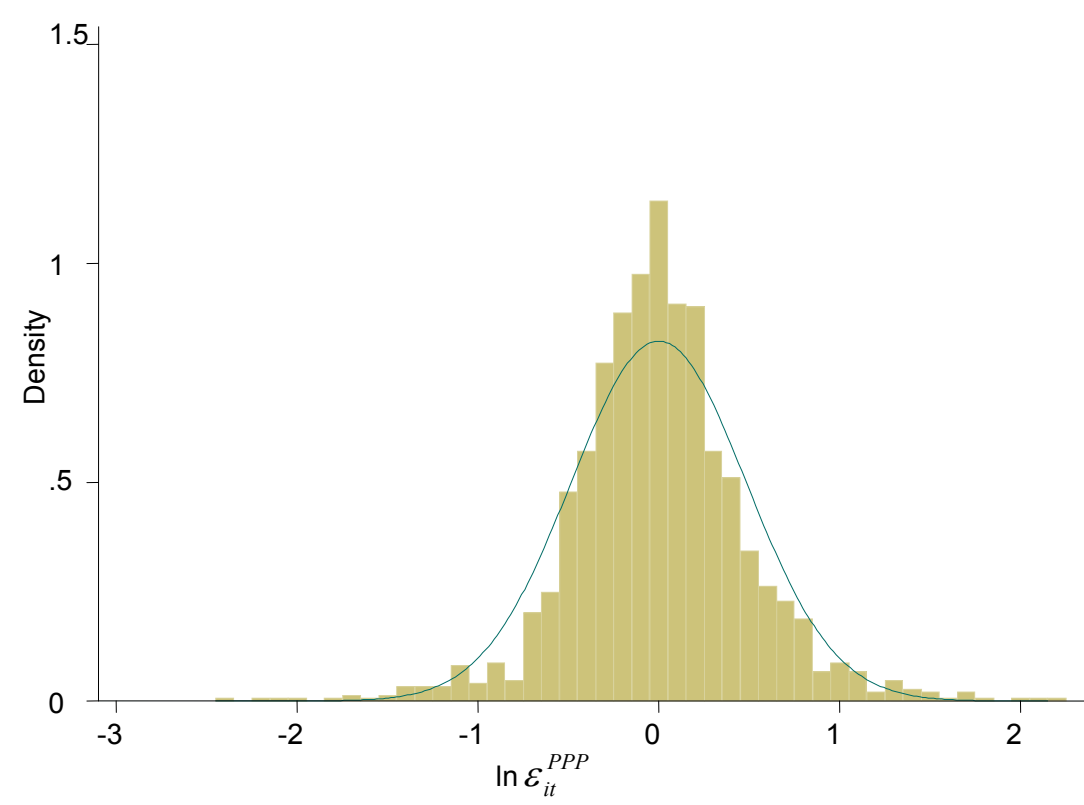

B. The FEER Undervaluation Index

Another approach to measuring under- (or over-) valuation relies on the notion of the fundamental equilibrium real exchange rate (FEER). This (called "equilibrium real exchange rate") was proposed and defined by Nurkse (1945) as the relative price of traded and non-traded goods that achieves simultaneously external and internal equilibrium. The general empirical approach is to relate the actual real exchange rate to a set of variables that influence that relative price in the medium or long term. Disagreements abound on how to estimate the FEER, notably about the relevant time horizon and hence relevant set of determinants. However, rather than reinvent the wheel, we follow closely the implementation of the IMF's consultative group on exchange rate issues (CGER) (IMF 2006), as well as recent applications to low-income countries in Christiansen et al. (2009). ${ }^{9}$

We thus estimate the fundamental equilibrium exchange rate by fitting the equation:

$$
e_{i t}=\alpha_{0}^{\prime}+\alpha_{1}^{\prime} y_{i t}+\alpha_{2}^{\prime} X_{i t}+\alpha_{t}^{\prime}+\varepsilon_{i t}^{F E E R}
$$

where $X_{i t}$ denotes "other fundamentals" that affect the FEER. In our main specification, and following the literature, these are the log of terms of trade (ToT), government consumption as a share of GDP, investment as a share of GDP, and openness.

\footnotetext{
${ }^{9}$ The literature is voluminous. For a review and references see IMF (2006) and Edwards and Savastano (2000). For recent applications to low-income countries, see Roudet and others, (2007).
} 
With the exception of the terms of trade (ToT), these additional variables are also from PWT6.2. For the ToT, we take advantage of an ongoing IMF project that is applying CGER equilibrium exchange rate analysis to low-income countries. As part of this project, a comprehensive database of commodity terms of trade for around 160 countries from 1960 was constructed on the basis of commodity price data and country-specific trade shares for 32 commodities. $^{10}$

The FEER regression results appear broadly consistent with the literature (Table 1). Both ToT and GDP per capita carry the expected negative sign as their improvement is often associated with real exchange rate appreciation. ${ }^{11}{ }^{12}$ This yields an undervaluation index $\hat{\varepsilon}_{i t}^{\text {FEER }}$ centered at 0 with a standard deviation of 0.46 (see Figure $1 \mathrm{~b}$ ).

Figure 1b. Distribution of FEER-based Misalignment

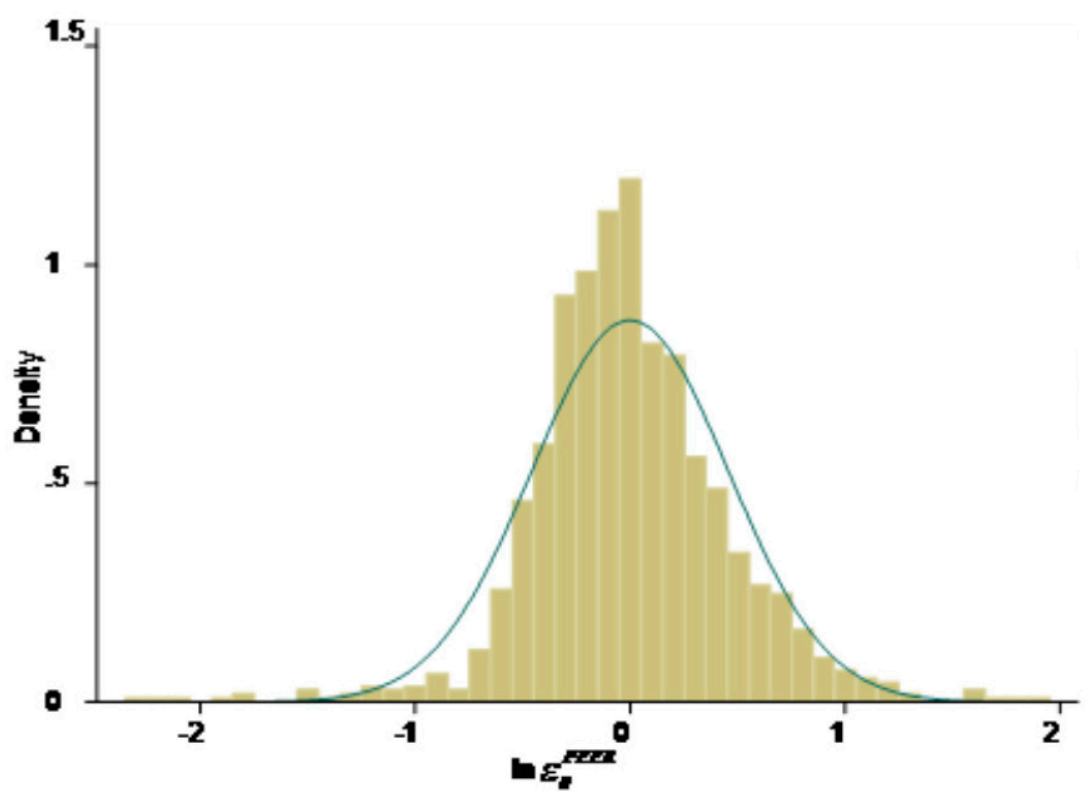

${ }^{10}$ These data are produced by and discussed in Christiansen and others (2009).

11 The expected signs on government consumption and investment are ambiguous, depending on the share of tradable goods in the relevant spending baskets. For example, if government spends relatively more on non-tradable goods, an increase in government consumption should lead to an RER appreciation.

${ }^{12}$ Following Rodrik (2008), we use OLS with time fixed effects. Because the real exchange rate is likely to be nonstationary, FEER regressions normally involves panel cointegration techniques such as vector error correction model (VECM), VAR, or dynamic OLS (DOLS). However - and critical for the calculation of the undervaluation index - the OLS coefficient estimators are consistent (indeed superconsistent), as long as we include the relevant cointegrating variables, notably per capita income, on the right-hand-side. However the estimates of the standard errors are not likely to be well-behaved. A panel bootstrap could yield small-sample estimates of these standard errors; however, these statistics are not a focus of this paper. 
The two indices $\hat{\varepsilon}_{i t}^{P P P}$ and $\hat{\varepsilon}_{i t}^{F E R R}$ are highly correlated, with a correlation coefficient of 0.96 (Figure 2). This is not surprising, given that (1) and (2) imply:

$$
\varepsilon_{i t}^{P P P}=\varepsilon_{i t}^{F E E R}+\alpha_{2}^{\prime} X_{i t}+\left(\alpha_{1}^{\prime}-\alpha_{1}\right) y_{i t}+\alpha_{0}^{\prime}-\alpha_{0}+\alpha_{t}^{\prime}-\alpha_{t}
$$

In other words, PPP-based misalignment differs from FEER-based misalignment for two reasons: (i) fundamentals that appreciate the equilibrium real exchange rate will cause PPP-based misalignment but not FEER-based misalignment (the $\alpha_{2}^{\prime} X_{i t}$ term); and (ii) the inclusion of fundamentals in the FEER implies different estimates of common "determinants" in the two concepts: the level of per capita income, the constant, and the time fixed effects.

This correlation presents a challenge to disentangling the effects of the two concepts, but it turns that this is not the only challenge.

Figure 2. Plots of the Two Undervaluation Indices

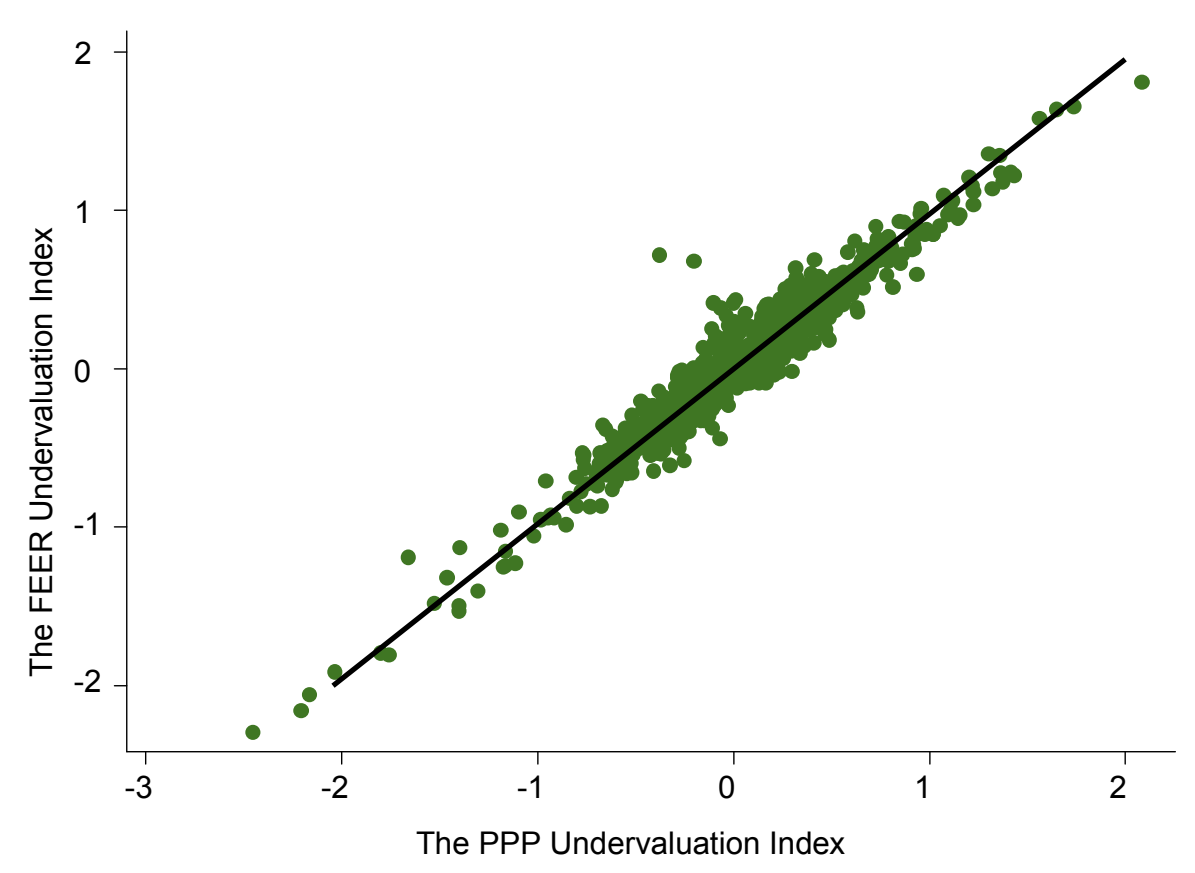

III. WHICH MISALIGNMENT DEFINITION MATTERS FOR GROWTH?

\section{A. Two Growth Models}

Rodrik (2008)'s main result is that overvaluation measured by $\varepsilon_{i t}^{P P P}$ reduces growth in a panel of developing countries. We replicate his basic result (Table 2 Column 1), regressing the 5 -year 
average growth rate on the undervaluation index, initial income, other standard growth determinants, and a full set of country and time dummies:

$$
g_{i t}=\beta_{0}+\beta_{1} \varepsilon_{i t}^{P P P}+\beta_{2} y_{i, t-1}+\beta_{3} X_{i t}+\beta_{i}+\beta_{t}+u_{i t}
$$

Initial income level, $y_{i, t-1}$, is included in the growth equation as neoclassical growth model and conditional convergence (Barro 1991) implies that initial conditions matter for growth performance. Variables $X_{i t}$ represent other determinants of growth. For most regressions in Rodrik, as in the first column of Table 2, these are excluded. Their inclusion does not make much difference for the estimated coefficient on $\varepsilon_{i t}^{P P P}$, but we will see that they turn out to be critical for its interpretation. ${ }^{13}$

Table 2. Growth and Undervaluations-A Horse Race

Dependent Variable: Growth

\begin{tabular}{|c|c|c|c|c|c|c|}
\hline & $(1)$ & $(2)$ & $(3)$ & $(4)$ & $(5)$ & $(6)$ \\
\hline Ln initial income & $\begin{array}{c}-0.066^{* * *} \\
(-6.25)\end{array}$ & $\begin{array}{c}-0.059 * * * \\
(-7.00)\end{array}$ & $\begin{array}{c}-0.059 * * * \\
(-7.23)\end{array}$ & $\begin{array}{c}-0.058 * * * \\
(-7.09)\end{array}$ & $\begin{array}{c}-0.058 * * * \\
(-6.89)\end{array}$ & $\begin{array}{c}-0.059 * * * \\
(-7.08)\end{array}$ \\
\hline $\operatorname{Ln} \hat{\varepsilon}_{i t}^{P P P}$ & $\begin{array}{c}0.024 * * * \\
(4.32)\end{array}$ & & $\begin{array}{c}0.022 * * * \\
(4.19)\end{array}$ & & $\begin{array}{c}-0.027^{*} \\
(-1.73)\end{array}$ & $\begin{array}{l}0.003 \\
(0.10)\end{array}$ \\
\hline $\operatorname{Ln} \hat{\varepsilon}_{i t}^{F E E R}$ & & $\begin{array}{c}0.025 * * * \\
(4.65)\end{array}$ & & $\begin{array}{c}0.021^{* * *} \\
(3.99)\end{array}$ & $\begin{array}{c}0.050^{* * *} \\
(3.21)\end{array}$ & $\begin{array}{l}0.020 \\
(0.73)\end{array}$ \\
\hline Ln Terms of Trade & & & $\begin{array}{l}0.003 \\
(0.29)\end{array}$ & $\begin{array}{l}-0.003 \\
(-0.34)\end{array}$ & & $\begin{array}{c}0 \\
(-0.06)\end{array}$ \\
\hline Openness & & & $\begin{array}{l}0.012 \\
(1.35)\end{array}$ & $\begin{array}{l}0.013 \\
(1.48)\end{array}$ & & $\begin{array}{c}0.015 * * * \\
(2.12)\end{array}$ \\
\hline Government Consumption & & & $\begin{array}{l}-0.002 \\
(-0.04)\end{array}$ & $\begin{array}{l}-0.007 \\
(0.19)\end{array}$ & & $\begin{array}{c}0.01 \\
(0.29)\end{array}$ \\
\hline Lag Investment & & & $\begin{array}{c}0.10^{* * *} \\
(3.30)\end{array}$ & $\begin{array}{c}0.074 * * \\
(2.41)\end{array}$ & & $\begin{array}{c}0.063^{* *} \\
(1.96)\end{array}$ \\
\hline Time Dummies & Yes & Yes & Yes & Yes & Yes & Yes \\
\hline Country Dummies & Yes & Yes & Yes & Yes & Yes & Yes \\
\hline Observations & 629 & 549 & 549 & 549 & 549 & 549 \\
\hline
\end{tabular}

Notes: Developing countries only (per capita GDP below $\$ 6,000$ ). The dependent variable is the log difference of 5-year misalignment implies that a 10 percent overvaluation lowers growth by 0.2 percentage point.

Robust t-statistics in parentheses

$* * *$ significant at $1 \%$ level; ** significant at $5 \%$ level; * significant at $10 \%$ level

${ }^{13}$ Excluding the $X_{i t}$ variables, we successfully replicate the same pattern of results, in both the full sample and that restricted to observations for which the terms of trade are available, as in Rodrik (2008). Undervaluation (1) has a significant positive coefficient both for all countries and in the subsample consisting of developing countries only; and (2) is insignificant in the subsample of richer countries with per capita GDP above \$6000. Rodrik (2008)'s results are trivially different from those reported in table 2 . He reported a coefficient estimate on undervaluation of 0.017 and a t-statistic of 5.21 in the full sample (1303 observations), and 0.026 and 5.84 in the developing country subsample (790 observations). 
In the WC growth model, in contrast, it is the deviations of the exchange rate from equilibrium that may matter for growth. Thus:

$$
g_{i t}=\beta_{0}^{\prime}+\beta_{1}^{\prime} \varepsilon_{i t}^{F E E R}+\beta_{2}^{\prime} y_{i, t-1}+\beta_{3}^{\prime} X_{i t}+\beta_{i}^{\prime}+\beta_{t}^{\prime}+u_{i t}^{\prime}
$$

The coefficients are "primed" to emphasize that they are not the same as in equation (4) - this is an alternate view of the data generating process.

When we estimate each of these models, we get similar results for the key parameters. In particular, undervaluation is significantly and positively associated with growth in developing countries. The estimated coefficients for $\beta_{1}$ is almost equal those of $\beta_{1}^{\prime}$. This is true when we omit the $X_{i t}$ variables, as in Rodrik (2008)'s main specification (Table 2 Column 2), and when we include the full set of $X_{i t}$ variables, (Columns 3 and 4).

\section{B. A Horse Race Between PPP- and FEER-Based Concepts of Misalignment?}

The regressions in Table 2 (Columns 1 to 4 ) yield similar results but support very different conceptions of misalignment. Empirically, which one is most relevant to growth? To answer the question, we are tempted to run a "horse race" between the two views of misalignment by including both measures of undervaluation in the following growth regression:

$$
g_{i t}=\delta_{0}+\delta_{1, P P P} \varepsilon_{i t}^{P P P}+\delta_{2, F E E R} \varepsilon_{i t}^{F E E R}+\delta_{3} y_{i t-1}+\delta_{4} X_{i t}+\delta_{i}+\delta_{t}+u_{i t}^{\prime \prime}
$$

However, this regression is not well defined. The reason is that equation (6) can be rearranged so that $y_{i t}$ is a linear function of $\varepsilon_{i t}^{F E E R}, \varepsilon_{i t}^{P P P}$, and the time fixed effects and constants. But from equation (3) this relationship is exact and $u_{i t}^{\prime \prime}$ is identically equal to 0 . Thus, all we can do with equation (6) is to rediscover the information in equations (1) and (2).

We can see this issue in another way that may shed some light on what to make of this problem. Suppose that the WC view of growth (as embodied in equation (5)) is correct, but we go ahead and estimate the "Rodrik" model (equation (4)) anyway. Because we know the true datagenerating process, we can infer what the estimated coefficients will be. ${ }^{14}$ Using equation (3) to substituting for $\varepsilon_{i t}^{F E E R}$ in equation (4), we find:

$$
g_{i t}=\beta_{0}^{\prime}+\beta_{1}^{\prime} \varepsilon_{i t}^{P P P}+\left(\beta_{3}^{\prime}-\beta_{1}^{\prime} \alpha_{2}^{\prime}\right) X_{i t}+\beta_{2}^{\prime} y_{i, t-1}+\Gamma_{i t}+\beta_{i}^{\prime}+\beta_{t}^{\prime}+u_{i t}^{\prime}
$$

where $\Gamma_{i t} \equiv \beta_{1}^{\prime}\left(\alpha_{1}-\alpha_{1}^{\prime}\right) y_{i t}+\left(\alpha_{0}-\alpha_{0}^{\prime}\right)+\left(\alpha_{t}-\alpha_{t}^{\prime}\right) \beta_{2} y_{i t}$.

\footnotetext{
${ }^{14}$ The coefficient will take these values in that, if the error term is reasonably well-behaved, an OLS regression will produce consistent estimates of these values.
} 
This implies the same regression (that is, the same regressand and regressors) as does the true model (excluding $\Gamma_{i t}$ ). Moreover, for the variables that are common to both growth models (equations 4 and 5), the implied coefficients are identical to the true coefficients, i.e. those in equation $4 . \Gamma_{i t}$ reflects the fact that omission of various relevant controls implies possibly different values for the constant, fixed effects, and coefficient estimates on common regressors. We can see that in practice that these differences are not important: the estimated coefficients on the common regressors (the Table only shows per capita income) are similar in column (3), which includes the $X_{i t}$ variables in the regression with $\varepsilon_{i t}^{P P P}$, are similar to those in column (1), which excludes those regressors.

Two important points emerge:

First, the coefficient on $\varepsilon_{i t}^{P P P}$ in this misspecified model is nearly identical to the coefficient on $\varepsilon_{i t}^{\text {FEER }}$ in the true model (equation 5). We observe nearly the same effect of misalignment on growth whether we measure it in the Rodrik or the WC fashion (comparing the coefficient on misalignment in columns 1 and 2 or columns 3 and 4).

Second, we get the "right" coefficient on the wrong misalignment variable because the difference between the two misalignment variables shows up in the coefficient on the regressors $X_{i t}$. These regressors account for the difference between the two concepts of misalignment, from equation (3).

Consider the effects of a unit increase in $X_{i t}$. Suppose that this causes both an appreciation of the equilibrium exchange rate and faster growth directly, so $\beta_{3}^{\prime}$ is positive and $\alpha_{2}^{\prime}$ is negative. Thus, in the true model, the full growth effect is the direct effect that is captured by $\beta_{3}^{\prime}$. From equation (2), the equilibrium real exchange rate appreciations, but so in general does the actual, and there is no misalignment effect on growth.

When-by assumption incorrectly - the Rodrik model of equation (4) is estimated instead of the true model, the increase in $X_{i t}$ causes two apparent effects on growth. Now, in addition to the direct effect, there is overvaluation of the exchange rate. The actual exchange rate appreciates, by equation (3). This causes $\varepsilon_{i t}^{P P P}$ to appreciate (take on a lower value, from equation (2)). At the same time, the coefficient measuring the direct effect of changes in $X_{i t}$ on growth, $\left(\beta_{3}^{\prime}-\beta_{1}^{\prime} \alpha_{2}^{\prime}\right)$, is higher by exactly the right amount to counteract the misspecified effect of this appreciation of $\varepsilon_{i t}^{P P P}$ on growth $\left(\beta_{1}^{\prime} \alpha_{2}^{\prime}\right)$. In terms of the effect of a change in $X$ on growth, two wrongs here make a right.

We see these effects with the actual data and regressions in Table 2 . The estimated coefficient on investment in the PPP-based specification (an element of $\hat{\beta}_{3}^{\prime}$ is 0.074 (Column 4), by assumption here the true model. Taking $\hat{\beta}_{1}^{\prime}$ from Column (4) of Table 2 and $\hat{\alpha}_{2}^{\prime}$ from Column (4) of Table 1, we can correctly predict that the coefficient on investment in the misspecified regression 
(column 3) will be $\hat{\beta}_{3}^{\prime}-\hat{\beta}_{1}^{\prime} \hat{\alpha}_{2}^{\prime}$ or $0.074-0.021 *(-1.3)=0.10 .^{15}$ Thus, the PPP-based model overstates the direct effect of investment on growth. Why? Because at the same time as investment directly increases growth, it leads to exchange rate misalignment which in that model reduces growth. To get the correct overall effect of investment on growth, the coefficient on the direct effect needs to be higher.

There is a parallel situation when in fact the Rodrik growth model is correct and - mistakenlythe WC growth model is estimated instead. Now, the truth is that the effects of $X$ do work in two ways. Suppose again that a given $X$ variable causes both an appreciation of the equilibrium exchange rate and faster growth, directly so $\beta_{3}$ is positive and $\alpha_{2}^{\prime}$ is negative. By equation (4), $X$ has a direct positive effect on growth and an indirect negative effect through the implied overvaluation (relative to PPP) that it causes. When model (5) is estimated by mistake, the coefficient on the (incorrectly defined) misalignment variable is the same as in the true model. However, the measure of misalignment used $\left(\varepsilon_{i t}^{F E E R}\right)$ does not indicate any overvaluation. Instead, the direct effect is smaller than the true model by the amount that is in fact due to misalignment.

To sum up, there is no way to tell from the data whether a change in $X$ works through a direct and an indirect effect (as in Rodrik) or just a direct effect; the two theories have identical empirical implications.

This result depends critically on the assumption that the same set of variables $X$ belongs both in the equilibrium exchange rate regression (3) and in the growth models (4) and (5). We return to this question below and look for some alternatives. However, in our view it is a priori very difficult to think of a variable that effects growth directly that by assumption does not also matter for the equilibrium real exchange rate, and vice versa. As to the first direction, any variable that effects growth may do so differentially across traded and non-traded sectors, and thus would matter for the real exchange rate (such is the justification typically given for variables such as government consumption and investment in the real exchange rate equation, even when the sign of this effect is unknown ex ante). The variables typically employed in real exchange rate equations cannot plausibly be excluded from a growth regression ex ante.

As an empirical matter, it is possible by omitting an $X$ variable from either the real exchange equation or the growth equation to pull an answer from the data. For example, if the $X_{i t}$ variables are excluded from the growth model (following the main specification in Rodrik (2008), then the horse-race (equation (6)) can be run (Column 5). In this case (which follows the baseline specification in Rodrik (2008) except for the inclusion of $\varepsilon_{i t}^{F E E R}$ ), the coefficient on $\varepsilon_{i t}^{F E E R}$ increases in magnitude and is highly significant, while $\varepsilon_{i t}^{P P P}$ has the unexpected negative sign. However, we do not see this as strong evidence in favor of the WC interpretation, absent good a priori reasoning for excluding the $X$ variables from the growth regression.

\footnotetext{
${ }^{15}$ Sampling error and the existence of $\Gamma_{i t}$, mean that this equality need not hold identically in the regressions.
} 
It is possible, if difficult, to rationalize differentiating the variables used in the growth and exchange rate regressions. In particular, investment takes time and growth regressions typically include them with a lag as the phenomenon has been well documented and referred in the literature as "time-to-build", "construction lag", or "gestation period" (c.f., Kydland and Prescott 1982; Majd and Pindyck 1987; and Bar-Ilan and Strange 1996). On the other hand, an effect of investment on the equilibrium real exchange rate would presumably be contemporaneous in that context. We implement these two assumptions in the "horse-race" regression shown in the sixth column of Table 2. The coefficient on $\varepsilon_{i t}^{F E E R}$ retains its magnitude while that on $\varepsilon_{i t}^{P P P}$ is very close to 0 , but the difference is not significant.

Clearly we should not make too much of these results. The link between investment and the real exchange rate in the real exchange rate equation is strong in our sample but is ambiguous in theory, and it is not significant (or results are not shown) in other estimated real exchange rate equations (Aguirre and Calderon 2005; IMF 2006; and Christiansen et al 2009). Moreover, investment might well determine growth contemporaneously in a 5-year sample. The fact that this creates endogeneity problems does not make including only the lag the correct response.

We draw three conclusions from this set of exercises. First, it is very difficult to disentangle empirically which measure of misalignment is the most relevant for growth, because the difference between the misalignment concepts is closely related to factors that also may drive growth directly. Second, insofar as we can disentangle the direct and the indirect effects of these other drivers, there is a bit of evidence in favor of the WC view: deviations from PPP are not important once deviations from equilibrium are controlled for. Third, making more empirical progress along these lines would require plausible specification of both the real exchange rate and the growth regressions. Such a specification search is outside the scope of this paper and perhaps not likely to settle the issue, as fully satisfactory specifications would likely be elusive. For example, the specter of reverse causality, particularly in the growth regression, is hard to convincingly dismiss. ${ }^{16}$ Thus, we return to our first conclusion.

\section{UNDERVALUATION VS OVERVALUATION}

There is another way to think about establishing which misalignment concept drives growth. A key difference between the WC and the Rodrik (2008) views on misalignment is that according to the WC view both undervaluation and overvaluation should be bad for growth. This implies that the sign of the coefficient on misalignment should switch signs depending on whether the exchange rate is under- or overvalued. According to Rodrik (2008)'s story, in contrast, overvaluation should be bad for growth and undervaluation good. Thus the sign is constant, and that the relationship between misalignment and growth is "symmetric".

\footnotetext{
${ }^{16}$ Our results, as in Rodrik (2008), may reflect reverse causality. The real exchange rate is in general endogenous, and in particular economic growth may influence the real exchange rate. Rodrik (2008) addressed this concern by presenting a dynamic panel estimation using GMM. Lagged values of regressors are employed as instruments for right-hand side variables and lagged left-hand side variables are also allowed as regressors in short panels (Arellano and Bond 1991).
} 
We find fairly broad support for Rodrik (2008)'s interpretation (Table 3). We cannot reject the hypothesis that the coefficient is invariant to the sign of the misalignment. As should not be surprising given the results of the previous section, this does not depend on which concept of misalignment is used. It also holds if (as a robustness check) we drop all the $X$ variables from the growth regression. One way to conduct such tests is to nest the hypothesis of a linear relationship - as well as other interesting hypotheses such as that the relationship is different for overvaluation and undervaluation observations - in a more general piecewise-linear specification. Thus, we add a series of interaction dummies for misalignment to the baseline growth regression, restricting our attention to the developing- country sample:

$$
\begin{aligned}
& g_{i t}=\beta_{0}^{\prime}+\beta_{2}^{\prime} y_{i, t-1}+\beta_{3}^{\prime} X_{i t}+\beta_{i}^{\prime}+\beta_{t}^{\prime}+ \\
& +\left(\theta_{1} D_{1}+\theta_{2} D_{2}+\theta_{3} D_{3}+\theta_{4} D_{4}+\theta_{5} D_{5}+\theta_{\theta} D_{6}\right) \varepsilon_{i t}+u_{i t}^{\prime}
\end{aligned}
$$

where $D_{1}$ is the dummy for extreme undervaluation of $100 \%$ or more; $D_{2}$ for large undervaluation between $50 \%$ and $100 \% ; D_{3}$ for small/moderate undervaluation of $50 \%$ or less; $D_{5}$ for large overvaluation between $50 \%$ and $100 \%$; and $D_{6}$ for extreme overvaluation of $100 \%$ or more. Notice that the base case is moderate overvaluation of $50 \%$ or less (the missing $\mathrm{D}_{4}$ ).

Table 3 presents the results for both concepts of undervaluation. A look at the estimated coefficients and standard errors suggests that there is little evidence of a significant difference in the values of the various coefficients on misalignment. In particular, overvaluation is bad and undervaluation is good for growth. This is confirmed by a set of hypothesis tests, presented in Table 4. 
Table 3. Undervaluation vs Overvaluation

Dependent Variable Growth

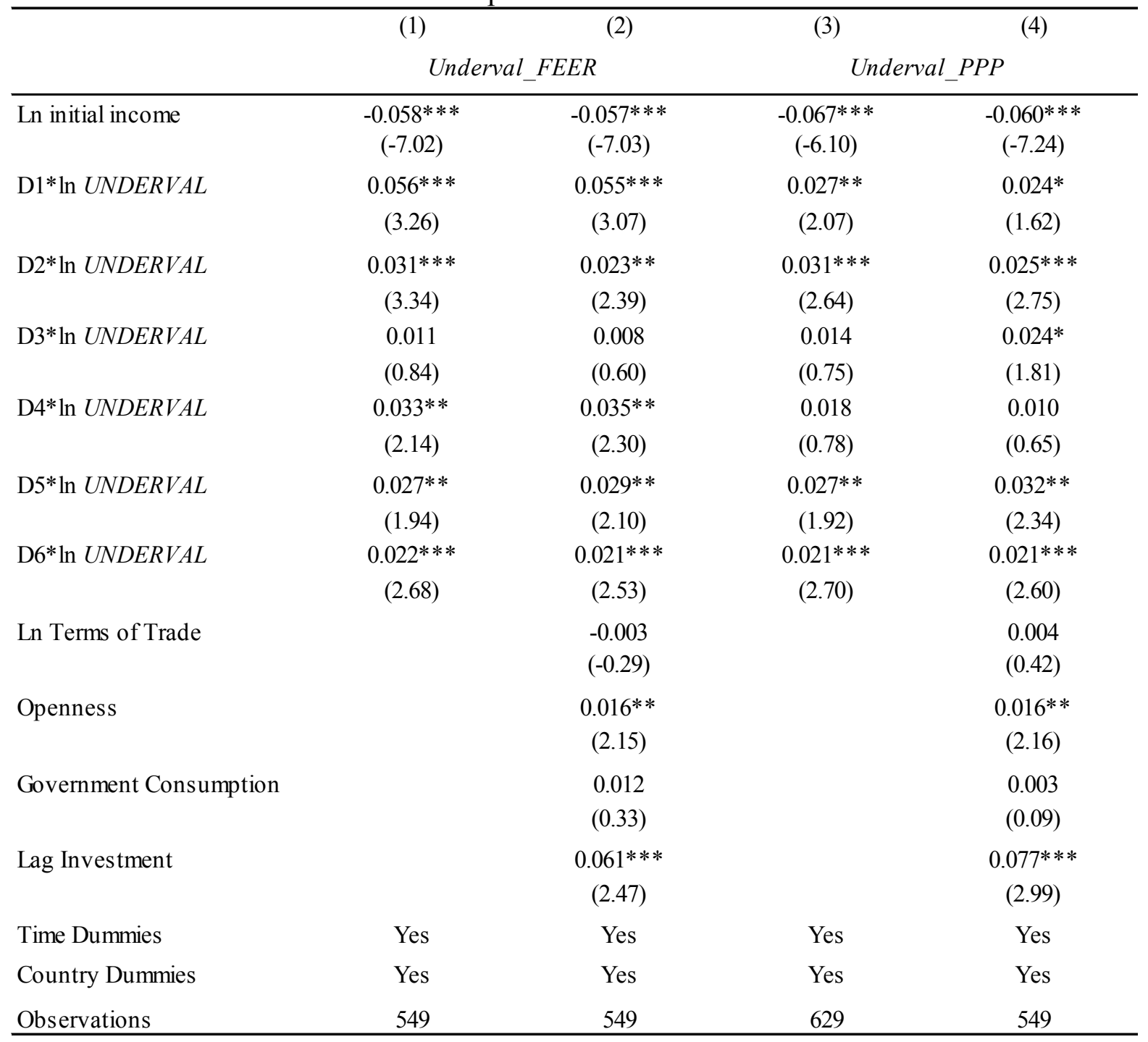

Notes: Developing countries only (per capita GDP below $\$ 6000$ ). Dependent variable is the log difference of per capita real GDP. D1 is the dummy for extreme undervaluation of $100 \%$ or more; D2 for large undervaluation between $50 \%$ and $100 \%$; D3 for small/moderate undervaluation of $50 \%$ or less; D4 for small/moderate overvaluation of 50\% or more; D5 for large overvaluation between $50 \%$ and $100 \%$; and D6 for extreme overvaluation of $100 \%$ or more. Robust t-statistics in parentheses.

$* * *$ significant at $1 \%$ level; $* *$ significant at $5 \%$ level; * significant at $10 \%$ level 
Table 4. Linearity and Symmetry Hypothesis Test

\begin{tabular}{|c|c|c|c|c|c|}
\hline \multirow[b]{2}{*}{ Null Hypothes is } & \multirow[b]{2}{*}{ Test } & \multicolumn{2}{|c|}{ Underval_FEER } & \multicolumn{2}{|c|}{ Underval_PPP } \\
\hline & & F-statistic & p-value & F-statistic & $\mathrm{p}$-value \\
\hline No effect of undervaluation & $\theta_{1}=\theta_{2}=\theta_{3}=0$ & $\mathrm{~F}(3,437)=4.47$ & 0.00 & $F(3,437)=2.63$ & 0.05 \\
\hline No effect of overvaluation & $\theta_{4}=\theta_{5}=\theta_{6}=0$ & $F(3,437)=3.61$ & 0.01 & $F(3,437)=3.51$ & 0.02 \\
\hline $\begin{array}{l}\text { Only extreme over- and } \\
\text { undervaluations matter, } \\
\text { possibly differently }\end{array}$ & $\theta_{2}=\theta_{3}=\theta_{4}=\theta_{5}=0$ & $\mathrm{~F}(3,437)=4.32$ & 0.00 & $F(3,437)=4.17$ & 0.00 \\
\hline $\begin{array}{l}\text { Only overvaluations matter, } \\
\text { and effect is linear in degree } \\
\text { of overvaluation }\end{array}$ & $\begin{array}{l}\theta_{1}=\theta_{2}=\theta_{3}=0 \\
\& \theta_{4}=\theta_{5}=\theta_{6}\end{array}$ & $F(5,437)=2.99$ & 0.01 & $F(5,437)=1.92$ & 0.09 \\
\hline $\begin{array}{l}\text { Only undervaluations matter, } \\
\text { and effect is linear in degree } \\
\text { of undervaluation }\end{array}$ & $\begin{array}{l}\theta_{4}=\theta_{5}=\theta_{6}=0 \\
\& \theta_{1}=\theta_{2}=\theta_{3}\end{array}$ & $F(5,437)=2.68$ & 0.02 & $F(5,437)=2.20$ & 0.05 \\
\hline
\end{tabular}

Notes: The hypothesis test is conducted based on growth regressions that include initial conditions, a full set of time and country fixed-effects, exchange rate misalignments, and fundamentals.

\section{Conclusion}

Why might the real exchange rate matter for growth? Rodrik (2008) argues that an exchange rate that is undervalued relative to that implied by purchasing power parity, after adjusting for per capital income, promotes growth. He argues that this undervaluation can help compensate for institutional weaknesses in developing countries that otherwise imply that the traded goods sector will be too small. Another tradition, embodied in the "Washington Consensus" (Williamson (1990)), argues that deviations from equilibrium are bad for growth, overvaluations because they imply external imbalance, undervaluations because they imply internal imbalance and excessive inflation.

The policy implications of these two views are very different. If undervaluation - even if driven by equilibrium factors - is good for growth, then this should considered in trying to influence those fundamentals. For example, inward transfers may cause overvaluation relative to PPP "Dutch disease" and thus have perverse unintended consequences on growth. Moreover, policies such as capital controls or intervention rules that may limit real appreciation could help long-run growth. If the WC view is right, however, then the emphasis should be on running policies consistent with medium-term internal and external balance, rather than on generating undervaluation. The analysis in an approach such as the IMF's "CGER" methodology should then be helpful in identifying problems. 
We attempt to use the growth regression framework of Rodrik (2008) to see which measure of misalignment is more important for growth. We reproduce Rodrik's PPP-based misalignment measure. We also estimate a measure based on deviation from the fundamentals that drive the equilibrium exchange rate, producing a Fundamental Equilibrium Exchange Rate (FEER)-based misalignment measure. We then try to see which of these two measures is more important in an otherwise standard 5-year panel growth regression.

It turns out that it is very difficult to disentangle empirically which measure of misalignment is the most relevant for growth. The differences between the misalignment concepts are due to the "fundamentals" that drive equilibrium exchange rates, and these same fundamentals plausibly also have a direct effect on growth. Either misalignment measure can be put into the growth regression; the estimated coefficients will be about the same. The misalignment values themselves are different, but there is an equal and opposite difference in the implied effect of the fundamentals on growth. In other words, in terms of misalignment on growth, the answer is the same no matter which definition is used. The effects of fundamentals on growth are also invariant to the definition of misalignment used. The only difference is that, with the Rodrik (2008) story, some of the effect of that fundamental on growth works through its effect on misalignment, the rest directly. According to the WC specification, the same net effect results entirely from direct effects on growth.

We attempt nonetheless to disentangle these two channels and find some weak evidence that the WC story is more consistent with the data. To tease this out requires the assumption that the set of fundamental determinants of the equilibrium real exchange rate is different from the set of variables that may drive growth directly. We suggest that lagged investment maybe be the appropriate investment variable in the growth regression, while concurrent investment makes more sense in the equilibrium exchange rate regression. Under these assumptions, we show that it is the variations in misalignment after taking into account fundamentals that matters for growth. Conditional on this WC misalignment, deviations from PPP do not matter.

We ourselves find this evidence no more than suggestive, given the lack of statistical significance and the difficulties in specifying these two equations convincingly. We thus step back and look at another feature of the results that may help resolve the question of which misalignment measure is more important for growth.

This feature is the linearity of the relationship between exchange rate misalignment and growth. According to a WC view, the impact of overvaluation is very different from that of undervaluation: overvaluation causes external imbalance, which may require lower growth to establish external balance; undervaluation may lead to "overheating" and excess inflation and should also be bad for growth in the medium run. For Rodrik, overvaluation is bad because it shrinks the traded sector, even if it is driven by fundamentals, while undervaluation is good for the same reasons. In other words, the relationship between misalignment and growth is linear. We reproduce Rodrik's result that, in the data, linearity holds. It is hard to square this result with the WC interpretation. Hard but not impossible: it may be that overheating supports growth over a five-year horizon, with the problems only coming later. Alternatively, undervaluation might be 
associated with below-potential output, so that higher-than-usual growth might be expected over the medium term as the economy returns to potential.

The main broad conclusion we draw is that much of the evidence in Rodrik (2008) does not really distinguish between the WC and the Rodrik views of the role of misalignment in growth. This leaves us with a less clear answer to our original question than we would have liked. Some of our regression evidence suggests that deviations from fundamentals are more important than deviations from PPP. On the other hand, undervaluations are also good for growth, a result squarely consistent with the Rodrik story but one that requires some gymnastics from the WC viewpoint.

Further progress may be possible in looking at this question with the current framework. Different growth regressions might help. However, the approach has severe limitations. As we have emphasized, strong assumptions are required to distinguish the two hypotheses. And surely important heterogeneity in the relationship between the real exchange rate and growth. Part of this is likely driven by omitted variables. For example, high domestic savings may be a driver of both the real exchange rate and growth. This sort of variation in undervaluation might be very different from that associated with terms of trade shocks, implying that our specification is too restricted. Some interesting hypotheses might be testable in a framework along the lines of Rodrik (2008), but many are not, given data and identification limitation. Ultimately, though, understanding the role of the real exchange rate for growth will probably require stepping away from the aggregate growth-regression framework employed here, in particular looking at more disaggregated evidence to see which channels are operating and perhaps to disentangle causality. 


\section{REFERENCES}

Aguirre, Alvaro, and Cesar Calderon, 2005, "Real Exchange Rate Misalignments and Economic Performance," Central Bank of Chile, Economic Research Division.

Arellano, Manuel, and Stephen Bond, 1991, "Some tests of specification for panel data: Monte Carlo evidence and an application to employment equations," Review of Economic Studies, Vol. 58, pp. 277-97.

Bar-Ilan, Avner, and William. C. Strange, 1996, "Investment Lags," American Economic Review, Vol. 86, pp. 610-22.

Barro, Robert J., 1991, "Economic growth in a cross section of countries," Quarterly Journal of Economics Vol. 106, No. 2, pp. 407-443.

Christiansen, Lone. E., Alessandro Prati, Luca Antonio Ricci, and Thierry Tressel, 2009, “External Balance in Low Income Countries," IMF Working Paper No. 09/221.

Dollar, David, 1992, "Outward-oriented developing economies really do grow more rapidly: Evidence from 95 LDCs, 1976-1985. Economic Development and Cultural Change, Vol. 40, No. 3, pp. 523-544.

Dollar, David and Aart Kraay, 2003, "Institutions, trade, and growth," Journal of Monetary Economics, Elsevier, Vol. 50, No.1, pp. 133-162, January.

Easterly, William, and Ross Levine, 2005, "National policies and economic growth" in Philippe Aghion and Steven Durlauf, editors, Handbook of Economic Growth, Elsevier.

Easterly, William \& Levine, Ross, 2003. "Tropics, germs, and crops: how endowments influence economic development," Journal of Monetary Economics, Elsevier, Vol. 50, No. 1, pp. 3-39, January.

Edwards, Sebastian, 1989. "Real Exchange Rates, Devaluation and Adjustment: Exchange Rate Policy in Developing Countries," Cambridge: MIT Press.

Edwards, S, Savastano, M., 2000. Exchange Rates in Emerging Economies: What Do We Know? What Do We Need to Know? In: Krueger, A.O., ed., Economic policy reform: The second stage. Chicago and London: University of Chicago Press, pp 453-510.

Fischer, Stanley, 1993, "The Role of Macroeconomic Factors in Growth," Journal of Monetary Economics, Vol. 32, pp. 485-512. 
Heston, Alan, Robert Summers, and Bettina Aten, 2006, Penn World Table Version 6.2, Center for International Comparisons of Production, Income and Prices at the University of Pennsylvania, September 2006, http://pwt.econ.upenn.edu/php_site/pwt_index.php

International Monetary Fund, 2006, "Methodology for CGER Exchange Rate Assessments," Research Department, November, http://www.imf.org/external/np/pp/eng/2006/110806.pdf

Jaewoo Lee, Gian Maria Milesi-Ferretti, Jonathan Ostry, Alessandro Prati, and Luca Ricci, 2008, "Exchange Rate Assessments: CGER Methodologies," IMF Occasional Papers No.261 (Washington: International Monetary Fund).

Johnson, Simon H., Jonathan Ostry, and Arvind Subramanian, 2007, "The Prospects for Sustained Growth in Africa: Benchmarking the Constraints," March, IMF Working Paper No. 07/52.

Henry, Peter Blair, 2008, Comments on Dani Rodrik. "The Real Exchange Rate and Economic Growth,” Brookings Papers on Economic Activity, 2, pp. 413-420

Krueger, Anne O., 1983. “Exchange Rate Determination”, Cambridge: Cambridge University Press.

Kydland, Finn E., and Edward Prescott, 1982, "Time to Build and Aggregate Fluctuations," Econometrica, Vol. 50, November, pp. 1345-70.

Majd, Saman \&, Robert S. Pindyck, 1987, "Time to build, option value, and investment decisions," Journal of Financial Economics, Elsevier, Vol. 18, No.1, pages 7-27, March.

Nurkse, Ragnar, 1945, “Conditions on International Monetary Equilibrium,” Essays in International Finance 4, Spring, Princeton, NJ: Princeton University Press.

Razin, Ofair, and Susan Collins, 1997, "Real Exchange Rate Misalignments and Growth," Georgetown University.

Rajan, Raghuram G., and Arvind Subramanian, 2007 "Aid, Dutch Disease, and Manufacturing Growth," Unpublished Paper, International Monetary Fund, August.

Rodriguez, Francisco, and Dani Rodrik, 2000, Trade policy and economic growth: A skeptic's guide to the crossnational evidence. In: Bernanke, B., Rogoff, K. (Eds.), Macroeconomics Annual 2000. Cambridge, MIT Press for NBER.

Rodrik, Dani, 2008, “The Real Exchange Rate and Economic Growth,” Brookings Papers on Economic Activity, 2, pp. 365-412. 
Roudet, S., M. Saxegaard, and C. Tsangarides, 2007, "Estimation of Equilibrium Exchange Rates in the WAEMU: A Robustness Approach,” IMF Working Paper No. 07/194.

Sachs, Jeffrey D., and Andrew M. Warner, 1995, "Economic Convergence and Economic Policies," NBER Working Papers 5039, National Bureau of Economic Research, Inc.

Wacziarg, Romain, and Karen Horn Welch, 2003, "Trade Liberalization and Growth: New Evidence," NBER Working Papers 10152, National Bureau of Economic Research, Inc.

Williamson, John, 1990, "What Washington Means by Policy Reform", in "Latin American Adjustment: How Much Has Happened?," John Williamson, ed. Washington, Institute for International Economics.

Woodford, Michael, 2008, Comments on Dani Rodrik, "The Real Exchange Rate and Economic Growth," Brookings Papers on Economic Activity, Vol. 2, pp. 420-439. 